\title{
A CONSTRUÇÃO DO SABER HISTÓRICO: HISTORIADORES E IMAGENS
}

\begin{abstract}
$\operatorname{Marcos}$ A. da Silva ${ }^{1}$
RESUMO: Este artigo analisa usos de fontes visuais, como cinema, pintura e fotografias, por historiadores brasileiros em pesquisas ainda ineditas. Ele discute dificuldndes experimentadas pelos profissionais de História ao utilizarem tais documentos e as conquistas representadas por esses esforços. Também incentiva a presença desse tipo de materiais na formaçấo universitária e na prática profissional dos graduados em História.
\end{abstract}

PALAVRAS-CHAVE: Pesquisa histórica, historia e pintura, história e filmes, historia e fotografia, história e imagens.

Há um trabalho do artista plástico Cildo Meireles, "Espelho cego", de 1970, que consiste em moldura de espelho comum, cujo vidro foi substituído por massa de calafate. Ele faz parte de uma série de obras elaboradas para serem fruídas por $\operatorname{cegos}^{2}$. Tal imagem poderia funcionar como involuntária metáfora sobre boa parte da pesquisa histórica em relação à visualidade, uma espécie de irônico "Monumento ao olhar do historiador", devido à escassa (ou nenhuma) atenção de muitos historiadores no que se refere a imagens. $\mathbf{E}$ frequente verificar que Teses e outros estudos pretensamente exaustivos sobre Imprensa ignoram ou indicam secundariamente o universo de fotografias, caricaturas e outras imagens ali contidas. A maior parte dos especialistas em História de São Paulo dos anos '20 age como se Tarsila do Amaral e Anita Malfatti, dentre outros, não fizessem parte, de forma ativa e fundamental, da historicidade do período ou só contassem num seu nicho bem isolado: a pintura modernista.

Essa charmosa segregação da visibilidade no exclusivo espaço da História da Arte se relaciona com vastas tradiçóes que se acostumaram a

1 Professor do Depto. de História da FFLCH/USP. Bolsista de Pesquisa do CNPq.

2 BRITO, Ronaldo. et al. - Cildo Meireles. Rio de Janeiro, FUNARTE, 1981. 
SILVA, Marcos A. da. A construção do saber histórico: historiadores è imagens.

associar Pesquisa His tórica a Imagens apenas através desse gênero específico ou num universo de "carência documental", quando se aborda sociedades cujas fontes escritas sâo de difícil ou impossível acesso.

Não se trata de menosprezar a vital importância da História da Arte para o Conhecimento Histórico como um todo nem de negligenciar os limites documentais efetivos que cada pesquisador enfrenta. Preocupa-nos a transformação do trabalho com o visual em tarefa exclusiva de alguns especialistas, sem um efetivo esforço dos Historiadores em geral para integrar tais objetos às suas discussões sobre o social.

Ao mesmo tempo, realçando a necessidade da Arte e de outras visualidades para qualquer Saber Histórico, não se pretende localizar alguma força messiânica em tais fontes nem colocar o textual sob suspeição. Trata-se, isto sim, de um esforço para ampliar o universo de documentação e análise do Historiador, jamais incentivando novos preconceitos ou negligências, preservando a preocupação com a identidade histórica da pesquisa nesse universo documental.

Isso significa que o visual é aqui considerado como dimensão de historicidade, sem se reduzir às perspectivas analíticas de outros campos de saber que com ela trabalham. Essas áreas de conhecimento são absolutamente legítimas em suas especificidades mas não resolvem as necessidades dos historiadores em relação às imagens porque: 1) Nem sempre se interessam por problemáticas de conhecimento histórico; 2)Requerem posturas ativas dos historiadores que as estudam para que ocorra um efetivo dialogo interdisciplinar e não um monólogo daquelas especialidades. Por esses motivos, consideramos mais frutífero falar em Multidisciplinaridade para caracterizar um debate de conhecimentos históricos com outros campos de saber, no qual, a História já entra evidenciando possuir preocupações com imagens, ao invés de transferir para aqueles a tarefa de definí-las.

Procuramos articular a discussáo sobre História e Retórica da Imagem a dimensões da formação dos profisionais de História e às suas práticas no exercício da profissão, quer no Ensino escolar, quer na Pesquisa acadêmica - preferencialmente, mesclando Ensino e Pesquisa.

No caso da formação dos profissionais, temos observado falhas que se manifestam especialmente quando formandos ou recém-formados são convidados a elaborarem projetos de pesquisa, o que se liga à raridade de atividades sistemáticas de pesquisa em Graduação, além da escassez de contatos com fontes visuais e bibliografia específica sobre as mesmas.

Quanto ao exercício da profissão, verifica-se limitações e timidez no apelo a materiais plásticos em Ensino e Pesquisa, reiterando-se, com frequência, seu uso na condição de "ilustração" de temas, numa perspectiva ingenuamente "realista", como se as imagens "retratassem" alguma História, o que 
não se restringe, evidentemente, à visibilidade. Tais deficiências se manifestam em tentativas de trabalho com pintura, fotografia e cinema, dentre outros materiais.

Em contrapartida, algumas pesquisas acadêmicas recentes e ainda inéditas rompem com essas limitaçôes, demonstrando possibilidades criativas de historiadores no trabalho com fontes iconográficas.

\section{Rindo da História.}

O texto de Meirelles ${ }^{3}$, dedicado à chanchada carnavalesca brasileira, procura recuperar experiências históricas por vias menos esperadas que a do cinema dedicado explicitamente a temas instituídos como História (governos Kubitschek, Quadros, Goulart ou Vargas, revoluções russa, "de ' 30 " ou francesa, guerras civis em Espanha e EEUU, etc.). Os filmes escolhidos se aproximam do histórico pela lente da paródia.

Em termos metodológicos, há certa hesitação do Autor entre privilegiar "novos objetos", para usar a consagrada expressão da coletânea organizada por Le Goff e Nora ${ }^{4}$, reforçando uma ótica que destaca tema e documentação na pesquisa histórica, e a preocupação com o ato de definir novas problemáticas, quer dizer, formular indagações a partir de projetos de conhecimento.

Nesse contexto, a definição dada às imagens ("acessível às grandes massas populares") se ressente de una escassa problematização. Embora seja louvável a preocupação com legitimar a presença de filmes no "elenco das fontes para o estudo da História", é preciso lembrar que aquela acessibilidade também significa ausência de debates sobre a linguagem enquanto tal, sendo ela, frequentemente, identificada a "reflexo" ou "transcriçăo - termos que Meirelles não usou - do real, com o risco de se perder a historicidade da questáo e diferentes níveis de leitura que múltiplas formas de expressão podem sofrer.

Evocando a dimensão industrial do cinema, Meirelles assumiu a interpretação de Morin para a mesma como indústria do sonho, que satisfaz

3 MEIRELLES, William Reis - Cinema e História - $O$ cinema brasileiro nos anos '50. Dissertaçấo de Mestrado em História, apresentnda ao ILHP/UNESP, Campus de Assis. Assis, Mimeografado, 1989.

4 LE GOFF, Jacques e NORA, Pierre (Dir.) - História - Novos objetos. Tradução de Terezinha Marinho. Rio de Janeiro, Francisco Alves, 1976. 
SILVA, Marcos A. da. A construção do saber histórico: historiadores e imagens.

carências imaginárias, afetivas ${ }^{5}$. Nuançando a tradição crítica à indústria cultural, na linha frankfurtiana, o Autor evoca o contexto nazi-fascista de sua elaboraçăo, sem levar em conta, todavia, a presença da experiencia norteamericana daquele grupo na elaboração da própria Dialética do esclarecimento ${ }^{6}$. Caberia, a partir dessas nuances, problematizar a expressão "testemunho do popular", tendo em vista que o filme mantém vínculos que não significam necessariamente continuidade em relação ao público, impondo temas, soluçōes e duração, além de centralizar a produção. Ao mesmo tempo, é possível pensar sobre papéis ativos do espectador, tentando resgatar reações a filmes. A separação entre aspectos de ordem material e intelectual, feita por Meirelles, se justifica como estratégia analítica mas requer discussões sobre desequilíbrios pois a primeira, através da produção, remete para assuntos, metragem e possibilidades técnicas.

A reiteração de temas como "incorporação das massas populares e das classes médias" e "populismo" também requer debates sobre modalidades de mobilização de massas anteriores aos anos '50, articulando-0s a controle e exclusão dos grupos populares. No mesmo sentido, a defesa por críticos dos anos '50 de conteúdos simples, populares e acessíveis sugere que se pense sobre políticas da indústria cultural naquele periodo (desejo de público amplo, dotado de certa homogeneidade, facilitando a centralizaçäo produtora) e as relações entre as mesmas e setores intelectuais de esquerda, como era o caso daqueles comentaristas.

A identificação da chanchada a "via de expressão" da cultura popular năo discute a produção centralizada, que destina ao público o papel de espectador, tornando duvidosa a simples condição popular daquela cultura.

$\mathrm{Na}$ discussão mais direta dos filmes escolhidos, Meirelles faz considerações técnicas sobre a documentação, abrangendo estado das fontes e classificação dos materiais, abordando também diferentes reações às chanchadas nos anos '50: havia rejeiçăo pelos críticos e grande aceitação pelo público. Em contrapartida, o Autor aponta os filmes valorizados por críticos liberais e.de esquerda: aqueles que abordavam "grandes feitos, grandes valores morais da sociedade". Trata-se de questão significativa para se refletir comparativamente sobre a produção de conhecimento histórico à época, levando em conta essa escala temática prestigiada.

5 MORIN, Edgar - Le cinéma ou l'homme imaginaire. Paris, Minuit, 1964.

6 HORKHEIMER, Max e ADORNO, Theodor W. - Dialética do esclarecimento. Traduçáo de Guido Antonio de Almeida. Rio de Janeiro, Jorge Zahar, 1985. 
Meirelles tende, com frequência, a apresentar sínteses conclusivas sobre seu material, sem explicitar, entretanto, seu percurso analítico. É assim que o tema do trabalho é recuperado nos filmes, com personagens diferenciados da força de trabalho almejada pelo capitalismo brasileiro daquele momento - figuras como autônomos, biscateiros, malandros e desclassificados são frequentes naquelas obras. Caberia pensar, entretanto, sobre esses tipos como integrantes efetivos do mercado de trabalho existente, recuperados para novos horizontes capitalistas. Além disso, eles fazem parte de tradições narrativas em teatro e humor no Brasil, englobando, p. ex., Manuel Antônio de Almeida e Arthur de Azevedo. Ao mesmo tempo, a realização de cada filme englobava relações de trabalho, exemplificadas em certas soluções de produção mais ou menos improvisadas. Depoimentos de atores que deles participaram, como Eliana, Zezé Macedo e Grande Otelo, poderiam contribuir para a recuperação desses vieses do trabalho.

Os ricos, por sua vez, foram caracterizados por Meirelles pelo ócio, postura que se fez presente em parte do Cinema Novo, de Cinco vezes favela ao próprio Terra em transe, com o último realizando registro paródico de segundo grau.

A pesquisa de Meirelles pensou prioritariamente na oposição entre a idéia burguesa de trabalho (organização, racionalização) e sua imagem nas chanchadas - desordem, precariedade. Trata-se de temática muito interessante, que também mereceria uma análise sob o ângulo de complementaridade daquelas perspectivas, dimensão ambígua de práticas sociais que instaurava, no nível das experiências, certa desordem racionalizada.

No mesmo sentido, o Autor tendeu a opor crítica a diversão, assumindo juízo sobre o espectador que ri de si como "auto-desprezo do povo", perdendo 0 alcance crítico de humor e escárnio enquanto figuras retóricas clássicas do riso ${ }_{4}$ presentes em análises de Aristóteles, Bergson, Freud e Olbrechts-Tyteca ${ }^{7}$. Em contrapartida, sua definição de chanchadas e programas de rádio como expressões de cultura popular que escapavam do controle burguês critica a imagem onisciente desse poder, caracterizando a cultura como espaço de tensões.

7 ARISTÓTELES - "Poética". Traduçño de Eudoro de Souzn, in: Metafísica é outros textos. Seleção de José Américo Pessanha. Ș̄o Paulo, Abril, 1984 (Pensadores). BERGSON, Henri - Le rire. Paris, Presses Universitaires de France, 1947. FREUD, Sigmund - Os chistes e sua relaçäo com o inconsciente. Tradução de Margarida Salomåo. Rio de Janeiro, Imago, 1977. OL BRECHTS - TYTECA, Lucie - Le comique du discours. Bruxelas, Université de Bruxelles, 1974. 
SILVA, Marcos A. da. A construçăo do saber histórico: historiadores e imagens.

Tal oscilação analítica também se manifesta no comentário sobre o filme "O camelô da rua larga", quando valores tradicionais são identificados a conservadorismo, deixando de considerar a possibilidade de tradições de luta, importantes para identidades populares, existirem ${ }^{8}$.

Vários dos temas presentes na análise de "Carnaval Atlântida" poderiam ser beneficiados pelo uso dos comentários de Bakhtin sobre o riso popular ${ }^{9}$ É o caso da sugestão para se fazer uma comédia carnavalesca partir de lixeiros negros, representados no filme por Colé e Grande Otelo: eles lidam com sujeira, o que, indiretamente, remete para o baixo corporal e, num outro sentido teórico, a inferioridade social como sujeira a ser escondida ${ }^{10}$

Essa possibilidade de abordagem também está contida na "Helena de Tróia" travesti: trata-se de sexualidade inesperada, em que convivem inversões e feiúra, atualizando a clássica paródia de Romeu e Julieta por Oscarito e Grande Otelo. Ainda nessa linha de convívio com baixo material e sombra, cabe lembrar o diálogo entre Grande Otelo e Colé sobre miséria que limpa o mundo, purifica-o, trazendo saída e alegria, e a recusa de outra Helena mulata, em nome de realismo (tem que ser branca, de tipo grego), que findou derrotada pelo irrealismo do imaginário carnavalesco.

As boas análises sobre esse e outros filmes contribuem para se ampliar o temário da discussão histórica sobre aquele período da sociedade brasileira, enriquecendo-o com referenciais iconográficos muito significativos.

\section{Faces da pintura erudita.}

A postura de Fagundes Jr. é muito diversa daquela de Meirelles na medida em que se apóia quase exclusivamente no estudo de imagens produzidas por Pablo Picasso ${ }^{11}$. O trabalho de Fagundes Jr. enfrentou diretamente o risco da cegueira historiográfica, assumindo importância redobrada na

8 V., p. ex.: V., p. ex.: THOMPSON, E. P. - A formaçāo da classe operária inglesa. Tradução de Denise Bottmann et al. Rio de Janeiro, Paz e Terra, 1987.

9 BAKHTIN, Mikhail - A cultura popular na Idade Mśdia e no Renascimento. Traduçâo de Yara Frateschi Vieira. São Paulo/Brasflia, HUCITEC/EdUNB, 1987.

10 Sobre a última questão, consulte-se: JUNG, Carl Gustav, et al. - O homem e seus símbolos. Tradução de Maria Lúcia Pinho. Rio de Janeiro, Nova Fronteira, sem data. VON FRANZ, Marie Louise - A sombra e o mal nos contos de fadas. Traduçâo de Maria Christina P. Kujawski. São Paulo, Paulinas, 1985.

11 FAGUNDES JR., Carlos Eduardo U. - O beijo da História - Picasso como emblema da modernidade. Tese de Doutoramento em Histórin Social, apresentada a FFLCH/USP. São Paulo, mimeografado, 1991. 
medida em que se dedicou à elaboração visual de grande alcance representada pela rica experiência daquele artista.

Trata-se de iniciativa ousada, tanto pela vastidão e complexidade do que Picasso produziu como pelas dificuldades que 0 acesso a essa produção oferece para um pesquisador brasileiro, tendo em vista sua concentração em museus europeus e norte-americanos. Além disso, o próprio trabalho de análise erudita de uma produção plástica tão culta quanto inovadora, como a de Picasso, oferece mais barreiras para quem enfrenta o desafio de abordá-la.

É um estudo caracterizado, portanto, pela coragem, tão necessária numa Academia ainda tímida como a brasileira. Junto como esse traço, o texto é marcado pela produção de certo "estranhamento", evidenciando seu próprio construir-se a partir de campos teóricos e artísticos (Pós-Estruturalismo e Pós-Modernidade, em especial) e resistências que partem de seu referencial básico - a produção de Picasso - e de seus intérpretes.

$O$ belo título atribuído à pesquisa se articula com dimensóes presentes em várias imagens daquele Artista: o casal, o encontro, a integração de diferenças que se intercambiam num toque. Ao mesmo tempo, ele sugere a problemática da Arte na História, da Arte face a outros níveis de historicidade, sob o signo daquela integração de diferenças. É certo que a expressão "emblema da contemporaneidade" possui dimensões ambíguas: para quem o Artista o é? Respostas dadas por Fagundes Jr. indicam a Arte de hoje e o próprio Autor do texto, ele mesmo Artista plástico.

Uma característica conceitual e analítica desse texto é o emprego de aspas em muitos termos, indicando seu uso problematizador - "sujeiton, "estilo", "procedimento", "obra", "tema". Seu uso excessivo fez com que se banalizasse, perdendo um pouco o sentido inicial: há tantas aspas que as palavras sem elas findaram se destacando! Por outro lado, o questionamento de certos pares conceituais ("tema"/"procedimento", p. ex.) resulta na superação de sua suposta pureza, instaurando novo estatuto para os mesmos. Preservando sempre as aspas, o texto evita resolver a questão ou o faz de forma que tende ao reducionismo - temas se tornam procedimentos unidirecionalmente...

Outra qualidade do texto é o desembaraço ensaístico que o marca, articulado a análises de obras específicas e lançando hipóteses gerais referentes ao percurso criador de Picasso. Trata-se de elemento criativo, talvez perturbador para certa mentalidade acadêmica ainda estreitamente monográfica.

Nesse estilo de reflexăo, há momentos marcados por falas digressivas, em que se descreve minuciosamente determinados Autores (Greenberg, Breton, Jakobson, etc.), com Fagundes Jr. perdendo a voz mais pessoal e 
SILVA, Marcos A. da. A construção do saber histớrico: historiadores e imagens.

apresentando quase fichamentos dessas leituras. Noutras ocasiōes, reitera-se afirmações, sugerindo identificações entre o Pesquisador e um traço picasseano - a retomada de problemas.

Uma carência mais grave diz respeito à discussão de Artistas que trabalharam simultaneamente a Picasso em relação a determinados problemas. Eles são citados muito lateralmente, de passagem, mesmo quando tiveram a imensa importância de um Bracque ou um Gris, para o Cubismo, um Miró, para o Surrealismo, ou um Klee, para a inclassificável metamorfose plástica moderna - poderíamos acrescentar Delaunay e Duchamp, dentre outros... O risco desse silêncio sobre outros grandes Artistas diz respeito ao espectro romântico do "gênio" retornar à medida que Picasso seja tratado isoladamente, como solitário personagem do percurso plástico moderno - e mesmo do pós-moderno já em elaboração.

Nossa crítica diz respeito ao diálogo estabelecido pela produção plástica (nảo nos referimos a supostos "roubos de idéias" ou "influências") daqueles Artistas em relação a problemáticas em comum. O exemplo mais evidente disso diz respeito ao trabalho simultaneo que Picasso e Bracque fizeram de reflexão pictórica sobre o legado de Cézanne, rumo ao Cubismo.

É também preocupante não se abordar a recepção de diferentes públicos àquela produção artística. Nesse sentido, a Tese é dedicada ao olhar do produtor, assinalando adequadamente conquistas e continuidades, refletindo pouco sobre modalidades de circulação e recepção, direta ou indireta, daquela produção. $O$ ângulo da recepção ajuda também a pensar sobre dimensões de historicidade que não se restringiram a "temas" ou "causas", evidenciando um papel ativo do artístico como agente de sensibilidade e percepçáo do mundo. Falar em "reinado puro do estético" sem levar em conta aquela ação do artístico como chave para outros mundos perde o contato com a elaboração do direito a diferentes visões a partir da invenção artística.

As reiteradas críticas da obra ao reducionismo são importantes e bem apoiadas no trajeto do próprio Picasso no que diz respeito à crise da História como referencial - em nosso entendimento, parte da crise maior do referencial na Pintura moderna. É evidente, nesse sentido, que falar sobre Pintura moderna e História não pode significar repetir o que se disse sobre a Pintura de um Jacques-Louis David ou um Eugéne Delacroix... O percurso da pintura moderna, especialmente no que diz respeito à superação de uma irredutibilidade de temas e procedimentos, introduz outras historicidades na cena plástica, que não se confundem com a Pintura Acadêmica de gênero histórico.

Nesse sentido, entendemos que a opção "temática" dos cubistas por cachimbos, chapéus ou instrumentos musicais é plenamente dotada de Historicidade e vieses políticos, compreendendo esses universos em chaves dife- 
renciadas da Pintura de gênero histórico ou da Política no espaço institucional: trata-se, afinal, de assumir um cotidiano de objetos comuns como índices de uma temporalidade e de sua anônima experiência.

Daí, nossa discordância quanto a considerar os anos ' 30 "inaugurais" para uma Pintura Política em Picasso. Em nosso entendimento, seria mais adequado falar num caráter "militante" daquela produção, que vai daquela década aos anos '50. Preferimos realçar que a auto-referenciação explícita na Pintura apre horizontes para Artistas e Públicos que significam uma Política como invenção imaginária permanente.

A crítica a um gesto interpretativo final é muito interessante, podendo ser desdobrada em diálogo com Foucault ${ }^{12}$. É a partir de um entendimento da infinitude da interpretação que o trabalho de Fagundes Jr. assume um caráter específico, onde os agentes da discussão se fazem muito presentes (Picasso, o Autor do texto, as tradições plásticas de Modernismo e Pós-Modernidade), recusando-se a uma explicação "final" de múltiplos fenómenos indicados.

Assim, a discussão sobre "fases" ou "mitologia" está repleta de sugestōes cujo elaborar-se histórico não foi explicado. Essa posição pode produzir efeitos interpretativos indesejados pelo Autor, como assumir uma trajetória contínua e teleológica do Artista (quando se articula as primeiras obras à "liberdade gestual de Avignon", p. ex.) ou apontar paradoxo inexplicado caso da obliteração da memória, que desagua em "memória verdadeiramente redentora".

No mesmo sentido teleológico, falar "'Les demoiselles d'Avignon', de 1907 , onde pela primeira vez no trabalho de Picasso se véem articuladas todas as linhas de sua interrogação futura" é estabelecer continuidade linear como destino do indivíduo Picasso, sem qualquer historicidade (no sentido de experiência, efetivo fazer) artística.

As reproduções incorporadas à pesquisa são excelentes em termos de cor e nitidez, incluindo indicações sobre dimensōes originais, de grande importancia para o leitor ter uma idéia da escala usada. Elas poderão ser desdobradas em alguns detalhes, eventualmente ampliados, que ajudarăo a acompanhar o olhar analítico de Fagundes Jr.. A presença de reproduções de alguns outros Artistas diminuirá o teor tendencialmente personalizante da problemática trabalhada.

12 FOUCAULT, Michel - Nietzsche, Freud e Marx / Theatrum Philasophicum. Traduçăo de Jorge Lima Barreto. Porto, Rés, 1975.FOUCAULT, Michel - Nietzsche, Freud e Marx / Theatrum Philosophicum. Traduçĭo de Jorge Lima Barreto. Porto, Rés, 1975. 
SILVA, Marcos A. da. A construção do saber histórico: historiadores e imagens.

O trabalho do Historiador com imagens recebe nessa pesquisa soluçōes de grande riqueza técnica e teórica, demonstrando a importância e necessidade de se enfrentar o visual como universo dotado de historicidade, malgrado todas as dificuldades que um acervo plástico tão complexo quanto a produção de Picasso possa oferecer.

\section{Olhares científicos.}

A análise conjunta de Saúde Pública e Fotografia, feita por Thielen a partir do acervo do Instituto Oswaldo $\mathrm{Cruz}^{13}$, abre outras possibilidades de interese para o conhecimento histórico, desdobrando-se em reflexões sobre Corpos, expostos e explorados para além de sua visibilidade imediata através da microfotografia; sobre Ciências, agentes daquelas reflexões, legitimadoras da exposição de intimidades e contatos físicos que o olhar da moral só assumia publicamente, no começo do século $\mathrm{XX}$, em determinados contextos artísticos; sobre Política como fundamental parte da definição de Povo, num momento histórico muito especial dessa noção - as décadas iniciais da República brasileira; sobre Espaços Naturais e Sociais, que constituíam o universo de implantação de múltiplos poderes modernos, desde antes da república; e sobre Artes, com suas batalhas entre mimese e imaginação, que Fotografia e Cinema reacenderam a partir de novos estímulos da Técnica, fertilizando outras linguagens.

Thielen organiza e analisa fotografias vinculadas à pesquisa de Saúde, tratando-as como documentos históricos. Os produtores originais daquela pesquisa já concebiam as fotografias como um tipo de documentaçăo comprobatória de sua cientificidade e eficácia. $\mathrm{O}$ historiador, retomando-as, tem a oportunidade de associar aquela produção a outras práticas sociais do período estudado.

O volume descreve o material fotográfico produzido pelo Instituto Oswaldo Cruz nas duas primeiras décadas deste século, abordando suas primeiras investidas urbanas (campanhas no Distrito Federal e noutros núcleos portuários), viagens de investigação, ações noutras áreas do país e auto-legitimação da Saúde Pública. Seus capítulos tenderam a separar esses temas cronologicamente, sem enfatizar sua simultaneidade dentro de um processo de constituição recíproca. Sua extrema concentração no acervo do apresentada a PUC/SP. Sāo Paulo, datiloscrito, 1992. 
próprio Instituto Oswaldo Cruz, compreensível diante de sua vasta riqueza, contribuíu para a perda da presença de outros exemplos fotográficos daquela natureza na Imprensa periódica, como foi o caso das notícias sobre a Expediçăo Rondon em Fon-Fon! e órgãos similares.

$O$ trabalho também se ressente de escasso debate historiográfico, o que contribuíu para a apresentação de alguns Autores (Carvalho, Stepan, Hardman, Sevcenko e Orleans e Bragança) na condição de fontes informativas, sem refletir sobre seus projetos interpretativos e pesos específicos, mesclando-os facilmente a porta-vozes da própria instituiçāo analisada ${ }^{14}$. Assim, argumentos pouco claros desses Autores năo foram debatidos, como é o caso de Carvalho falando que "O inimigo não era a vacina em si", sem demonstrar o que seria tal essência, ou da citação de documentos atribuída a Hardman, cujo conteúdo não foi exposto, perdendo-se sua articulação com o tema tratado.

Thielen explicitou sua opção pela análise das fotografias como "registro de práticas humanas", em busca das "variáveis que se encontram por trás do ato de fotografar". Cabe lembrar que as fotografias não apenas registravam práticas humanas, elas mesmas o eram. Daí, ser possível pensar em sua sociabilidade como algo que não está somente "por trás do ato de fotografar" mas nesse próprio ato.

Sua preocupação com o entendimento dessas atividades de saúde e dos usos da fotografia como exemplos das "primeiras políticas públicas do país" é pertinente e poderia ser ampliada através de reflexões sobre o espaço polf́tico republicano, que se implantava também através daqueles usos e atividades, e mesmo de políticas sociais esboçadas anteriormente no Brasil, caso dos Congressos Agrícolas e das expedições científicas de estrangeiros no século XIX.

A comparaçấo formal entre microfotografia e produções artísticas modernas (Kandinsky, Klee, minimalistas) é atraente mas, também, perigosa: enquanto esses pintores eram grandes construtores de respostas para a crise do referencial nas artes plásticas, via abstração (Kandinsky) ou elaborações extremamente específicas à superfície pintada (Klee), os cientistas e seus

CARVALhO, José Murilo de - Os bestializadas. Stro Paulo, Cia. das Letras, 1988. STEPAN, Nancy - Gênese e evoluçĩo da ciência brasileira. Rio de Janeiro, Artenova, 1976. HARDMAN, Francisco Foot - Trem fantasma. Săo Paulo, Cia. dhs Letras, 1988. SEVCENKO, Nicolau - A revotta da vacina. São Paulo, Brasiliense, 1984. ORLEANS E BRAGANÇA, Joăo - "Introduçấ", in: VASQUEZ, Pedro-Dom Pedro II e a fotografia no Brasiḷ. Rio de Janeiro, Index, sem data. 
SILVA, Marcos A. da. A construção do saber histórico: historiadores e imagens.

fotografos findavam enfatizando o referencial, apresentando até o que era "invisível a olho nu". Em sentido semelhante, a adequada aproximação etimológica entre imagem e imaginação requer indicações sobre sua aplicabilidade à fotografia científica: os pressupostos realistas desta năo colocam a imagem, frequentemente, contra a imaginação?

A falta de debate sobre esses ítens contribuíu para que o trabalho năo problematizasse argumentos auto-legitimadores da fotografia - "congelar 0 tempo", "reproduzir (...) a realidade", "cópia", "prova cientifica da verdade". Ao mesmo tempo, a oposição entre o belo e o verdadeiro, feita por Koch a favor da fotografia científica no final do século passado, poderia servir de base para se debater as relaçōes entre Arte e Ciência, que o trabalho fotográfico tanto atualiza através do apelo a poses, enquadramentos, iluminações e outros recursos de linguagem.

A comparação de caricatura a fotografia contém grandes potencialidades mas foi pouco explorada, inclusive por năo se reproduzir exemplos caricaturais no volume. Os efeitos de imagem diferem nos dois suportes, certamente, mas houve presença de conflitos e tensões (tão patentes nas caricaturas) também em fotografias, como demonstrado em vários exemplos desse trabalho. Cabe lembrar que Oswaldo Cruz, embora tenha sofrido certas rejeiçōes e sido caricaturado depreciativamente quando iniciou os trabalhos de saneamento no Rio de Janeiro, transformou-se rapidamente em herói cultural da Imprensa, inclusive em alegorias de que participava o personagem caricatural Zé Povo. O cotejo entre tais linguagens é prejudicado por Thielen quando ele caracteriza a fotografia através da "necessidade de se conformar à realidade visível": tal apreciação sugere uma visibilidade universal prévia, reiterada pela fotografia, desprovendo a última de qualquer força instituinte.

Os comentários sobre o "homem comum do interior do país" são muito bons no que diz respeito a se pensar sobre o cotidiano dessa face histórica, ainda pouco estudada entre nós, e também para refletir sobre o olhar dos fotógrafos, muito atento para o universo institucional naquela série (igrejas, escolas, clubes, jornais), elegendo a cidade litorânea como padrão, invertendo a clássica imagem do sertanejo antes traçada por Euclides da Cunha. A hipótese das oposiçóes entre urbano/primitivo-pobreza, associadas à dicotomia beleza/feiúra, foi articulada ao projeto de civilizar o mundo do atraso, exemplificado nas fotografias em que as mesmas pessoas, em diferentes momentos, figuraram bem arrumadas ou descalças. Tal atitude fotográfica pode também significar que o universo apresentado já abrigava civilização e primitivismo, cabendo reforçar a primeira - e as instituiçōes fotografadas eram outros instrumentos desse processo.

O último capítulo do estudo se inicia com a fotografia de grupo de médicos no Restaurante Assírio do Teatro Municipal, Rio de Janeiro, num 
jantar homenageando Arthur Neiva, caracterizando a imagem como "retrato do poder médico brasileiro no ano de 1916". Evidentemente, parte desse poder está contido na fotografia. Muito dele, todavia, não se fez tão visível, a começar pelos empregadores dessas autoridades médicas. A identificação dos poderes da Saúde Pública a "dever social da nacionalidade" evidencia como os médicos lutavam por mais poderes, que estavam além de sua atuação profissional restrita e que transformavam suas principais instituições (Faculdades, Institutos, etc.) em uma espécie de "Universidade Antecipada", onde se abordava questões científicas e sociais as mais diversas, em perspectivas interdisciplinares - o que também ocorria em cursos de Engenharia...

A vontade de poder expressa pelos médicos abrange, também, a crítica da política, tão presente em setores da cultura brasileira das décadas iniciais deste século (a ficção de Lima Barreto, os ensaios históricos de Manoel Bomfim, o personagem Zé Povo e a Campanha pelo Serviço Militar Obrigatório), demonstrando a disseminação desses projetos no social como proposta para o país. O Autor opôs o viés conservador da Saúde à modernidade das "fotografias em movimento", embora tenha reconhecido que o primeiro cedeu à segunda. Pode ser mais frutífero evitar essa oposição rígida, uma vez que os argumentos da saúde são um importante ponto de articulação entre ambos: atingem fins conservadores através de instrumentos modernos. Além disso, existe historicamente conservadorismo ou modernidade em estado puro?

Seria também conveniente refletir mais sobre a produção de imagens de pessoas, especialmente, quando se apresentou sequências de etapas de doenças em eliminação a partir do tratamento ministrado pelos cientistas do Instituto Oswaldo Cruz. Nesse caso, caberia discutir recursos como pose, expressão facial, vestimenta, ambientação e iluminação.

A grande riqueza desse acervo contribui para que muitas questóes permaneçam inexploradas. Sugerimos que Thielen pense mais sistematicamente sobre o olhar metropolitano (dos cientistas vindos da capital federal) organizando predominantemente essas imagens, procurando identificar outros olhares ("do interior", "do campo", "das pequenas cidades", "da pobreza"?) atuando naquele processo. Junto com isso, observa-se na atuação do Instituto Oswaldo Cruz o paulatino abandono dos diagnósticos raciais sobre os problemas do país e a identificação de um universo econômico-social a ser higienizado e fortalecido. Nesses termos, a instituição parece formar tradições para pensar sobre questões nacionais desde seu início, o que pode ser articulado a suas lutas mais recentes, contra a ditadura militar (anos '60) e pela redemocratizaçảo (anos ' 80 ). 
SILVA, Marcos A. da. A construção do saber histórico: historiadores e imagens.

\section{Retratos do trabalho.}

A atenção de Dias em relação à imagem fotográfica do trabalho no jornal paulistano A Gazeta contribui para se superar certa ênfase excessiva a poucos outros jornais de São Paulo nos anos ' 30 e ' $40^{15}$. Além desse aspecto, a escolha de $A$ Gazeta é importante para o conhecimento da História da Imprensa em São Paulo devido ao peso que tal jornal possui no periodismo da cidade até hoje, como se observa pelo funcionamento de uma emissora de rádio e outra de televisão com seu nome, um Curso de Jornalismo (anterior ao da ECA/USP) e uma Fundação Casper Líbero e o próprio diário Gazeta Esportiva.

Os critérios de periodização adotados no trabalho, embora anunciados desde o título, permaneceram ambíguos. Por um lado, 1930 e 1945 remetem

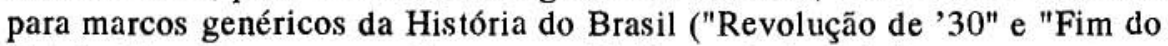
Estado Novo"), sem se explorar especificidades do jornal. Por outro, o texto destacou muito o "Estado Novo", citando-se mesmo a sequência cronológica $1930 / 1937$ e $1937 / 1945$.

Dias apontou seu interesse pelas "relações do Estado frente às questões políticas e sociais", tendendo a privilegiar o Estado em suas discussões, reiterando uma ótica do próprio "Estado Novo".

A bibliografia trabalhada é pertinente, estando prejudicada por algumas omissões no que se refere àquele período ${ }^{16}$, donde a preservação da noção "oligarquia", que evita o conceito de classes sociais (e de luta de classes...), deixando de problematizar argumentos como "valorização do trabalho". Embora tenham sido utilizadas aspas para se falar em "'reabilitação' do trabalhador" e "domesticar o caráter (do trabalhador tipicamente nacional)", não se evitou misturas entre a análise feita e falas estadonovistas.

15 DIAS, Odete da Conceição - O trabalho no discurso fotográfico de "A Gazeta (1930-1945). Dissertação de Mestrado em História Social, apresentada a FFLCH/USP. São Paulo, datiloscrito, 1993.

16 ANTONACCI, Maria Antonieta M. - Vitória da razão? São Paulo, Marco Zero/CNPq, 1993. CHAUf, Marilena - "Apontamentos para uma crítica da Ação Integralista Brasileira", in: CHAUf, Marilena e FRANCO, Marin Sylvia Carvalho - Ideologia e mobilização popular. Rio de Janeiro, Paz e Terra, 1978, pp 17/149. DE DECC:A, Edgar e VESENTINI, Carlos A. - "A revoluçåo do vencedor". Ciência e Cultura. São Paulo, SBPC, 29 (1): 25/32, jan 1977. MUNAKATA, Kazumi - A legislação trabalhista no Brasil. Sâo Paulo, Brasiliense, 1982. SILVA, Zélia Lopes da - A domesticação dos trabalhadores nos anos '30. São Paulo, Marco Zero/CNPq, 1990. 
Na própria bibliografia utilizada, faz-se necessário um debate sistemático em determinados trechos. É o caso da passagem: "os representantes da imprensa tinham objetivos bem determinados mas a luta social e polftica os obrigava a se desviarem do caminho pré-estabelecido: a cada passo enfrentando situações novas que exigiam reformulações de suas propostas"17. É claro que os "objetivos bem determinados" faziam parte da "luta política e social" pois não se conhece exemplos de Imprensa externa a sociedade. 0 próprio texto de Dias sintetiza opinião de Casper Líbero, segundo a qual "a imprensa era mais um veículo organizado de acordo com princípios morais e éticos, objetivos, do que um órgão inserido no interior de uma complexa rede de práticas político-ideológicas" (p 48). Como se vê, aquele trecho citado repõe uma auto-imagem de Líbero, cabendo à análise histórica identificar significados sociais de tais argumentos.

Noutra citação, comentou-se que "num país de analfabetos, a estampa tem a sua função eficaz" ${ }^{18}$. Essa frase reafirma pressuposto corrente na Imprensa brasileira sobre o visual como material acessível para analfabetos, o que se observa em notas de Fon-Fon! e Careta na primeira década do século. Caberia pensar sobre a Imprensa instituindo uma interpretação de imagens, voltada para determinados objetivos sociais e políticos, e discutir o visual como código estruturado, que exige interpretações de seus consumidores, analfabetos ou não.

Em sentido similar, a ênfase de Sontag e Kossoy ao referente, endossada por Dias, merece ser complementada por reflexóes sobre o olhar do fotógrafo e da sociedade à qual ele pertence, que organiza interpretações através da escolha de ângulo, corte, luz, ampliação - como, de resto, o próprio Kossoy salienta naquele mesmo livro ${ }^{19}$

A Autora realça a "importância política e social (...) delegada (ao trabalho) pelas diretrizes estadonovistas", sem debater o sentido desse argumento numa ditadura. Esse problema se manterá ao longo do volume, especialmente, quando se faz referências ao Estado Novo como "forma de

17 Dias extrafu esse trecho de: CAPELATO, Maria Helena Rolim - Os arautas do Liberalismo. São Paulo, Brasiliense, 1989, p 13.

18 IDEM, Obra citada, p21, reproduzinclo comentário de $A$ Gazeta.

19 Alguns clíssicos sobre a interpretaçâo de imagens são: ARNHEIM, Rudolf - El pensamiento visual. Tradução de Rubén Masera. Buenos Aires, Eudeba, 1973.FRANCASTEI, Pierre - Peinture et societé. Lyon, Audin, 1951. PANOFSKY, Erwin - Significado nas artes visuais. Traduçáo de Maria Clara Kneese e J. Guinsburg. São Paulo, Perspectiva, 1976. Os textos indicados de Sontag e Kossoy são: SONTAG, Susan - Ensaio sobre fotografia. Rio de Janeiro, Arbor, 1981. KOSSOY, Boris - Fotografia e História. São Paulo, Ática, 1989. 
SILVA, Marcos A. da. A construção do saber histórico: historiadores e imagens.

representação dos operários" (frase atribuída a Vargas, sem indicação de fonte, na p 139), desdobradas na menção a políticos, militares e religiosos que desempenhavam tal função (p 151), culminando na síntese: "trabalhador (...) representado pelas classes dominantes" (p 158).

Essa questão convida a refletir sobre o que significa "representação" numa ditadura - o Estado Novo -, onde não havia eleições, partidos nem Congresso funcionando.

A rígida separação entre Imprensa de Elite e Imprensa Sensacionalista (p 37) requer demonstração. Líbero atribuíu o sensacionalismo ao "imediato interesse público" (p 62) mas cabe ao historiador refletir sobre esse argumento no campo das relaçóes sociais de que ele fez parte. Afinal, esse sensacionalismo era, antes de mais nada, de interesse empresarial, pois vendia jornais, e era produzido por especialistas - escritores ou fotógrafos.

No mesmo sentido, a caracterização do popular (p 63) requer nuances e mediações. A Gazeta, como órgão cultural e agência política (no sentido gramsciano, produtora de hegemonia), classificou certos espaços na condição de "populares" - feiras, periferia, interior, crimes. Diante do jornal, como intérprete, é imprescindível que o historiador reflita sobre a questão do popular, dialogando com tradições historiográficas que se dedicaram ao tema $^{20}$.

A polaridade entre elite e sensacionalismo, por um lado, e a imagem do popular, por outro, convidam a discutir os conceitos de "povo" e "popular" trabalhados nesse estudo, necessidade aumentada ainda mais quando Dias evoca aproximações entre o jornal e "interesses populares" (p 132), com $\boldsymbol{A}$ Gazeta mediando relaçōes ehtre Estado e povo ou cuidando "dos interesses do povo" (p 134), o que corresponde mais a auto-imagem da publicação.

É importante lembrar, para refletir sobre essa visão do tema, que Miguel de Arco e Flexa falou num trabalho de "limpeza moral" assumido pela publicação $^{21}$, o que remete para campanhas de racionalização, eugenia e higienização da época, desenvolvidas pelo IDORT e por outras instituiçōes, que visavam a novos controle e expropriação de homens pobres.

20 BORNHEIM, Gerd, et al. - Cultura brasileira - Tradiçäo/Contradição. Rio de Janeiro, Jorge Zahar/FUNARTE, 1987. RUDE, George -Ideologia e protesto popular. Traduçăo de Waltensir Dutra. Rio de Janeiro, Zahar, 1982. SAMUEL, Raphael, et al. - Historia popular y Teoria Socialista. Traduçåo de Jordi Beltran. Barcelona, Crifica, 1984. WILLIAMS, Raymond - Marxismo e Literatura. Tradução de Waltensir Dutra. Rio de Janeiro, Zahar, 1979.

21 FLEXA, Miguel de Arco e - 1906-1954 - 48 anos de A GAZETA. Sem indicaçes. 
É nesses quadros que argumentos estadonovistas sobre "representação" ou "proteção do homem brasileiro" (p 67), para não falar de "reabilitação do papel do trabalhador" ( $\mathrm{p}$ 92), assumem seu caráter propriamente totalitário, abrangendo a definição de um "soldado do trabalho"22.

É necessário marcar mais claramente, portanto, as diferenças entre a argumentação analítica e as justificativas dominantes como estratégias de poder no período.

As fotografias trabalhadas apresentaram imagens do governo e de questões sociais (alimentação e moradia) mais diretamente vinculadas por Dias à visão sobre o trabalhador. No último caso, a Autora analisou as fontes a partir de procedimentos como analogia, ocultamento e falsa homologia, evidenciando uma leitura crítica desses materiais. Dois exemplos dessas atitudes são considerar a abordagem dos últimos.temas como estratégia para "garantir a vendagem de todos os dias" ( $p$ 134) e, nas análises de fotografias sobre $o 1^{\circ}$ de maio, a transformação de agentes governamentais em personagens mais importantes, além da redução dos operários a passivo pano de fundo (p 146).

Nesse campo temático, que torna concreta a presença do trabalhador em tal discurso fotográfico, seria enriquecedor traçar paralelos com ítens bibliográficos que abordam moradia, saúde, alimentação e educação antes de 1930 ou depois de 1945 , ampliando a historicidade dos problemas pesquisa$\operatorname{dos}^{23}$.

O interesse dessa documentação também será ampliado com a inclusẫo de informaçôes sobre os fotógrafos que trabalhavam no jornal e o processo de trabalho em termos de divisão de tarefas e edição das imagens.

\section{Depois do elogio, as cobranças.}

A pluralidade das linguagens visuais trabalhadas por Meirelles, Fagundes Jr., Thielen e Dias incentiva a pensar sobre os universos que eles abriram para a reflexão histórica. Nesse sentido, o desejo de ver os suportes plásticos que seus trabalhos exploraram sendo interpretados pelo máximo de

22 Recherches (Le soldht du travail). Paris, Recherches, 32/33, nov 1978.

23 ROLNIK, Raquel - "De como Sấo Paulo virou a capital do capital", in: VALLADARES, Lácia do Prado (Org.) - Repensando a habitaçäo no Brasil. Rio de Janeiro, Zahar, 1983, pp 109/134. BRITES, Olga - "História e Educaçîo em 'Sesinho' ". Revista Brasileira de História. Såo Paulo, ANPUH/Marco Zero, 9 (19): 57/80, set 1989 / fev 1990. 
SILVA, Marcos A. da. A construção do saber histórico: historiadores e imagens.

historiadores tem grande campo para cobranças aos pesquisadores que ainda não incorporaram tais documentos às suas investigações.

Outras cobranças, todavia, podem e devem ser também endereçadadas àqueles que, como oş quatro historiadores aqui comentados, já enfrentam o desafio da pesquisa histórica baseada em fontes visuais. Uma delas, frequente ao longo do presente texto, diz respeito à efetiva discussão historiográfica por esses pesquisadores, quer para criticar o silêncio dos historiadores que nấo trabalham com o visual, quer para demonstrar a contribuição que sua ousadia trouxe em termos de problemáticas de conhecimento histórico.

Nesse sentido, o apelo a diferentes imagens pelos historiadores não pode significar a ausência de debates sobre procedimentos metodológicos básicos de seu campo de saber, indicando a pertinência daqueles materiais a séries de documentos, articulando-os a contextos sociais em que atuaram e atuam, garantindo o efetivo debate crítico com diferentes patrimónios e memórias.

A utilização de imagens pelo historiador, ao lado de seu fascínio e riqueza, também significa novos desafios para quem pretende efetivá-la. Mas esse é um "preço" que qualquer pesquisador paga, seja qual for sua documentaçåo. Quem se habilita?

\footnotetext{
ABSTRACT - This article analyses the uses of visual sources, such as movies, paintings and photos, made by Brazilian historians in unpublished works. It discusses some of the difficulties involving such uses and its meanings as steps foward in historical research. It also encourages the use of such materials in the learning process of History administrated to unclergraduate students as well as in everyday teaching and research practice.
}

KEY-WORDS: Historical Research, History and Painting, History and Moovies, History and Photographs, History and Images. 